\title{
WORKPLACE RELATIONSHIPS AS A SYMPTOM OF ORGANIZATIONAL CULTURE AND A LEVER FOR CULTURE TRANSFORMATION
}

\author{
Olga Tararukhina \\ Ph.D., Saint Petersburg State University (Russia)
}

\begin{abstract}
This theoretical paper proposes an original approach to transforming organizational culture through the lever of workplace relationships. It explores the concept of organizational culture at five levels, from the most visible to the most deep and fundamental, the complexity of workplace relationships, their kinds and types. It further articulates how workplace relationships appear as a symptom of organizational culture, and how culture, both societal and organizational, influences interpersonal relationships at work, as well as lives in those relationships, and how a company's culture can be influenced and transformed through workplace relationships.
\end{abstract}

Keywords: Organizational culture, workplace relationship, professional relationship.

\section{Introduction}

Comparative meta-analysis of theoretical and empirical studies of workplace relationships in four societal cultures - in United States, China, Russia, and Sweden - revealed significant differences not only in how relationships work, but also in the place they occupy in the culture: value, purpose, key characteristics of workplace professional relationships, even time perspective, are very different (Tararukhina, 2016). It confirmed that the ways people hold and develop relationships, are reflective of societal culture. Culture and relationships are intertwined: relationships reflect culture, culture sustains and evolves through relationships. By nature of what culture is, organizational culture can also be reflected through workplace relationships: through processes of internal adaptation (Schein, 2004), employee behavior in the workplace (Cooke, 2015).

In the last decade, the subject of organizational culture has been getting more attention in popular business publications and magazines, as well as academic research, aiming to harness the power of culture in helping the company achieve significant business results, or in getting in the way of company's abilities to deliver. Yet, one of the carriers of culture, and levers of its transformation, workplace relationships, is typically left out of equation, giving the floor to the level of teams and groups. This paper proposes an original theoretical approach, that is based on empirical and theoretical research, as well as practical consulting work, to leveraging workplace relationships for culture transformation.

\section{State of the art}

Currently, the phrase "organizational culture" seems to be used so loosely that it may mean run the gamut between leadership effectiveness, employee engagement, reputation, climate, communication. Under these circumstances, it is only natural that when it comes to culture change, it would defer to the tools from traditional change management (primarily training and communication) or organizational design, at best.

Literature review shows an abundant amount of research and theories about human activity in the workplace, including fields like trust or motivation, and rather broad areas of leadership, negotiations, communication, conflict resolution, influence. These approaches are aiming to approach professional relationships through the perspective of the individual's skills, abilities, and personality and behavior; or through group dynamics and team effectiveness approaches, none of which were not intended to address the dyadic level of dynamics in organization.

With a few exceptions (such as Schutz, 1966, 2004; Fiske, 1992; Schein, 2004), most of those approaches fail to get to the core of what a relationship is in the workplace: what it consists of, and what is this intangible element that seems to make or break the effectiveness of task execution: some things get longer to execute and take more resources than others. However, when it comes to culture transformation, even these researchers seem to focus on the organizational and individual level, as opposed to dyadic level of culture. 


\subsection{Organizational culture transformation}

Existing approaches to culture transformation follow the way their authors understand the culture itself. Many propose change management approaches to the process that evolves and transforms, but doesn't change "like a used car" (Katzenbach, 2012). Some would say that it is semantics, but transformation suggests transforming at the core, while change suggests replacement of an element.

Organizational culture constantly evolves, while also remains whole and complete in each moment. That is achieved through culture also being a system of a complex set of elements at different levels. Even when some elements of culture could be perceived as healthy or dysfunctional, these elements are a part of one system, they are in relationship with one another: they reinforce, balance, support, hinder etc. Any one element (e.g. behavior X) is deeply interconnected and may even be interdependent with others (value X and behavior Y). Eliminating one is not only impossible (it will be re-installed by the rest of the system), it is also impractical: even when seen as dysfunctional, it is a source of past success, stability, and meaning. Therefore, there is no culture that one can prescribe as good for every company out there; culture is organization-specific, nor can it be simply replaced by another, there needs to be a thoughtful approach that appreciates and leverages the evolutionary nature of culture, that helps it evolve to the desired state without making the "old" one wrong or bad.

\subsection{Organizational culture and workplace relationships}

There have been several substantial approaches proposed to articulate the way organizational culture determines and rules relationships. Schutz $(1966,2004)$ identified interpersonal needs (inclusion, control, and openness) that are defined behaviorally in action and feeling, as well as directionally: self-other, other-self, and self-self. According to Schutz (2004), these dimensions at all levels determine what culture could deliver the best performance when individuals have their interpersonal needs met (based on the needs). This approach refers to one-to-many dynamics when it comes to the organizational culture work. However, interpersonal needs appear to hold important in the one-to-one dynamic as well.

Fiske $(1992,2019)$ proposed that people in all cultures use these models to organize much of their everyday social cognition according to four kinds of relationships:

- market pricing: "relationships are oriented to socially meaningful ratios or rates such as prices, wages, interest, rents, tithes, or cost-benefit analyses" (Fiske, 2019),

- authority ranking: "people have asymmetric positions in a linear hierarchy in which subordinates defer, respect, and (perhaps) obey, while superiors take precedence and take pastoral responsibility for subordinates" (Fiske, 2019),

- communal sharing: "a relationship in which people treat some dyad or group as equivalent and undifferentiated with respect to the social domain in question" (Fiske, 2019), and

- equality matching: "people keep track of the balance or difference among participants and know what would be required to restore balance" (Fiske, 2019).

These four kinds can describe all relationships within certain situations: the same pair of relationship partners can engage in all four of those in the same day, depending on the situation they are in and the subject they are interacting about.

Schein (2004) proposed that individuals create assumptions through answering questions about the proper ways to relate to each other in order to make the group safe, comfortable, and productive:

- about identity and role in the group (Who am I supposed to be in this group and what will be my role?);

- about power and influence in the group (Will my needs for influence and control be met?);

- about needs and goals (Will the group's goals allow me to meet my own needs?);

- about acceptance and intimacy in the group (Will I be accepted, respected, and loved in this group? How close will our relationship be?).

This approach allows to see how individual can adapt to, and be included into the group, a relationship between one-to-many. However, this approach arguably does not translate very well to the the dyadic level, one-to-one interpersonal relationship, where both individuals create dynamics from the beginning, there is nothing to be included in, both relationship partners by nature of what is an interpersonal relationship, create one "from scratch". The social needs articulated by Schein (2004), appear relevant to the one-to-one relationship as well.

\section{New perspectives / contributions}

From the brief overview above, it becomes clear that the theory of organizational culture needs clarification in terms of its determining professional relationships and being reflected through them, which would also allow for the development of a culture transformation approach that is grounded in social processes of culture rather than change management. Research on workplace relationships (or professional relationships) needs to address the phenomenon of the relationship itself at the dyadic level, as opposed to indirect description and studies of what influences them: there needs to be more clarity as to what a professional relationship consists of, how it develops, what are its kinds etc. 
This paper presents an attempt to meet all three requests.

\subsection{Original theory of organizational culture}

Schein (2004) proposed a model of organizational culture that consists of three levels: artifacts, espoused behaviors and values, and underlying assumptions. The proposed theory suggests that there is a need for more specificity, for discernment of layers of Schein's level 2, "espoused behaviors and values". Those are distinctly different layers of culture, because: 1) they have different functions; 2) they are experienced differently, and 3) they have a different impact. We can observe a behavior, such as a smiling (or not) coworker coming up to us in the hallway; we know what the norms and rules are in each kind of meeting, what is expected of each role in each meeting; and after we got used to the culture, we almost never question why we do what we do, what's important about doing it the "way we do it around here".

By making this clarification, the proposed model of organizational culture has 5 layers, that like layers of an onion, reveal culture from its most visible elements (language, space, symbols) to the most latent ones (basic assumptions):

Figure 1. "Onion" model of the five layers of organizational culture.

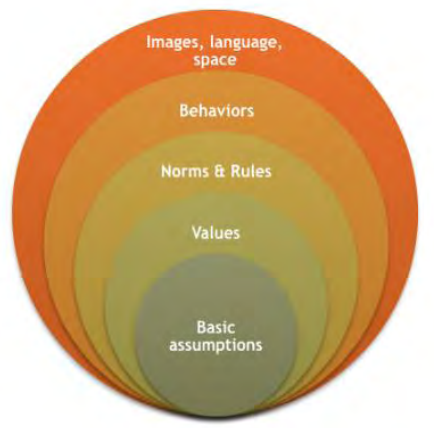

In this model, the layers represent:

- Images / language / space: observable, tangible materials and objects;

- Behaviors: observable actions people take in interactions and in doing their work;

- Norms: shared understanding of the distinction between what's right and wrong, what's acceptable and what's not; Rules: dos and don'ts as well as knowing or the ability to forecast their consequences;

- Values: what is held important when members of the organization take action;

- Basic assumptions: beliefs that we assume to be true and do not question or typically even discuss.

Following Schein's definition, culture in this model is also defined as "the shared way things are done around here" that develops through socialization, trial and error on the way to success. Its key functions are to make things predictable, familiar; to explain what things mean; to determine what to pay attention to and what to react to, and how to act/react; to keep the organization's memory about what leads to success, stability and meaning (Schein, 2004).

It is also important to underscore what does not appear in the description above. Since culture evolves through socialization, through learning from other people about culture of a specific organization (e.g. incumbents enculturate newcomers), and as a result of this learning process, culture not only lives in group meetings, it gets transmitted and transformed through the vehicle of interpersonal workplace relationships: they are an important carrier of organizational culture.

\subsection{Original theory of workplace relationships}

What is unique about workplace relationships, is that they are both personal and professional, they develop in the context of organizational and societal culture, they are influenced by the roles relationship partners play (e.g., boss and employee), there is an implied and explicit hierarchy that may be different from the hierarchy in the society where the relationship takes place. To add another dimension to an already complex system, consider this: one can't end a professional relationship, unless they change the company; and coworkers change roles: today's boss can be a peer tomorrow. Add to the picture politics and potential incivility, as well as emergent introduction of robots, and we get the contemporary system of professional relationships.At work, employees have several types of relationships, main four include: with the immediate manager, with peers we have immediate work with in common, other leasers in the organization, and other peers who we don't share immediate work. Professional relationships that are connected through hierarchy or through work in common are stronger than those that are only connected through belonging to the same organization. 
Presented here original approach to the concept of workplace relationships (Tararukhina, 2016), is focused on the relationship itself, its quality, not the relationship partners as individuals or their behaviors. First, according to our theory of workplace relationships (Tararukhina, Gurieva, 2015; Tararukhina, 2016), they consist of:

- Clarity: understanding roles of relationship partners, as well as each other's' identities and motivation;

- Significance: attributing value, importance to the other person (both as a person and as a coworker);

- Trust: ability to confide in the other, be vulnerable to their actions, take the risk on them;

- Closeness: intensity, flow of exchange of thoughts and feelings with each other; experience of being connected.

Second, there are four kinds of relationships (Tararukhina, 2016): the degree to which relationship is focused on meeting the yearnings of each relationship partner, determines where and how the satisfaction with the relationship is tilted between them in a difficult situation, when there is tension between relationship partners. The kinds of relationships are:

- Imposing and Pleasing: one of the partners insists that their yearnings (Wright and Wright, 2012) be met at the expense of the other; one of the partners insists that the yearnings of another be met at the expense of their own;

- Resonance: both partners successfully meet the yearnings of each other and treat them as equally important to both of them;

- Dissonance: both partners retreat from meeting their own and the other's yearnings.

All four kinds of relationships exist in all organizations, so to understand culture through relationships, we need to understand not only the prevailing kinds of relationships, but also how each of these relationships reflects the layers of culture, what is more common for a specific organization, and what is this organization's unique "flavor" of each kind of relationship. These kinds of workplace relationships show up in all the layers of culture, from language to basic assumptions, and can reflect culture as its symptoms. They are also symptoms of societal cultures (Tararukhina, 2016, 2019a, b, c).

To identify that, the following questions need to be answered:

- What are the language, behaviors, norms/rules, and values of Imposing and Pleasing in this organization?

- What are the language, behaviors, norms/rules, and values of Resonance in this organization?

- What are the language, behaviors, norms/rules, and values of Dissonance in this organization?

\subsection{Original approach to transforming organizational culture through workplace relationships}

Culture transformation typically is thought of in conjunction with a big shift in business strategy, or market, or political environment. There is also a natural transformation that occurs in organizational cultures, as the company grows, matures, and evolves. It takes place at all levels - organizational, team level, and at the dyadic level (in interpersonal relationships). At organizational level, culture integrates (honoring consistency of the sum of parts, "overarching culture") and differentiates (honoring diversity of subcultures). At the team/group level, the focus is on increasing group performance through productivity and culture. At the dyadic level, it appears as influencing culture by choices about what dots to connect, what questions to ask and focus on, what to highlight as important, what to reinforce. These micro-moves can create significant shifts over time. It happens both formally and informally; sources of power help the influence, as well as closeness of the relationship, through intersubjectivity (Buber, 1992).

When new employees join the group, the organization has to enculturate them. It is also on the new members/employees to seek to learn new culture. One of the most important things newcomers learn is the rules of engagement in their new organization. Professional relationships are actually one of the most tangible ways to experience and understand what organizational culture is like, as well as go to the meetings. When culture is transforming, relationship partners can lean on their relationships quality (determined by trust, closeness, significance, clarity) to navigate from the old towards the new culture:

- At the Behaviors layer: relationships moderate observable actions;

- At the Norms and Rules layer: relationships are a locus of meaning making;

- At the Values layer: relationships provide relative importance of actions and results, from the perspective of the new culture, help outline, underscore the importance and meaning of the new culture.

\section{Practical implications}

This approach provides a more tangible and grounded way to achieve successful culture transformation in organizations than change management and communication alone, because it leverages the element of culture that connects the individuals at the most human level, their yearnings. This approach is agnostic of industry and kind of company, which makes it very flexible for organizational leaders to 
understand and execute. It can help organizational leaders inform their leadership styles, increase their versatility and relational skills, and help others do the same.

\section{Originality and value}

This approach and theory, contrary to most known to us, concerns with the quality of professional relationships, their content, kinds, and development, and how they reflect organizational culture; though that, this approach proposes an original perspective on culture transformation that has the potential to be more powerful and sustainable than behavior training alone.

\section{Questions for future research}

Going forward, one avenue of research could be to identify whether there is a correlation between the kinds of business strategies and kinds of workplace relationships, due to the significant relationship between organizational culture and business strategy.

\section{References}

Boisnier A., Chatman j. (2002). The role of subcultures in agile organizations. Retrieved from http://faculty.haas.berkeley.edu/chatman/papers/20_CulturesSubculturesDynamic.pdf

Buber M. (1992). On intersubjectivity and cultural creativity. Chicago and London: The University of Chicago Press.

Cooke R. (2015, October). How Culture Really Works. Paper presented at the 1st Ultimate culture conference. Chicago, IL.

Fiske A.P. (1992). The four elementary forms of sociality: Framework for a unifying theory of social relations. Psychological Review, 1992, Vol. 99, N 4, 689-723.

Fiske A.P. (2019). Human Sociality. Retrieved from http://www.sscnet.ucla.edu/anthro/faculty/fiske/relmodov.htm

Gibb J. (1991). Trust. A new vision of human relationships for business, education, family, and personal living. Newcastle Publishing, CA.

Katzenbach J. (2012). Culture change that sticks. Harvard Business Review. July-August 2012. Retrieved from https://hbr.org/2012/07/cultural-change-that-sticks

Kluckhohn F.L., Strodtbeck F.R. (1961). Variations in value orientations. Row, Peterson and Company.

Lewin K. (1997). Resolving social conflicts. Field theory in social science. (Reprinted ed.) American Psychological Association.

Myasishchev V.N. (1995). Psihologiya otnoshenij. [Psychology of relationships]. Moskva-Voronezh: NPO MODEHK.

Obozov N.N. (1979). Mezhlichnostnoe obshchenie. [Interpersonal interaction]. Leningrad: Izdatel'stvo LGU.

Quinn R.E. (1996). Deep change: Discovering the leader within. John Wiley \& Sons.

Schein E. (2004). Organizational culture and leadership. (3rd ed.) San Francisco, CA: John Wiley \& Sons.

Schutz W. (1966). The interpersonal underworld. Science \& Behavior Books, Inc.

Schutz W. (2004). The human element. Business Consultants, Inc.

Tararukhina O. (2016). Cross-cultural variations in satisfaction with interpersonal relationships in the workplace. Doctoral dissertation, Saint Petersburg State University, Saint Petersburg, Russia. Retrieved from http://www.dslib.net/soc-psixologia/kross-kulturnye-osobennostiudovletvorjonnosti-mezhlichnostnymi-otnoshenijami-v.html

Tararukhina O.V., Gurieva S.D. (2015). Social'no-psihologicheskaya model' razvitija mezhlichnostnyh otnoshenij v organizacii [Social-psychological model of development of interpersonal relationships in the workplace]. // Sovremennye issledovaniya social'nyh problem. 2015, 1 (21), 26-40.

Tararukhina O. (2019, March) a. Specifics of Workplace Relationships in Russia. Paper presented at the third biennial International Convention of Psychological Science (ICPS). Paris, France.

Tararukhina O. (2019, March) b. American Business Culture through the Lens of Workplace Relationships. Paper presented at the third biennial International Convention of Psychological Science (ICPS). Paris, France.

Tararukhina O. (2019, April) c. Workplace Relationships as Symptoms of the US Business Culture. Paper presented at the annual meeting of Midwestern Pryschological Association. Chicago, IL.

Worley C., Williams T., Lawler E. (2014) The agility factor: Building adaptable organizations for superior performance. San Francisco, CA: Jossey-Bass.

Wright, R., Wright J. (2012). Transformed! The science of spectacular living. Nashville: Turner Publishing. 